\title{
Demographic Patterns and Outcomes of Patients in Level I Trauma Centers in Three International Trauma Systems
}

\author{
Amy C. Gunning ${ }^{1} \cdot$ Koen W. W. Lansink ${ }^{1} \cdot$ Karlijn J. P. van Wessem $^{1}$ • \\ Zsolt J. Balogh ${ }^{2} \cdot$ Frederick P. Rivara $^{3} \cdot$ Ronald V. Maier $^{4} \cdot$ Luke P. H. Leenen ${ }^{1}$
}

Published online: 17 July 2015

(c) The Author(s) 2015. This article is published with open access at Springerlink.com

\begin{abstract}
Introduction Trauma systems were developed to improve the care for the injured. The designation and elements comprising these systems vary across countries. In this study, we have compared the demographic patterns and patient outcomes of Level I trauma centers in three international trauma systems.

Methods International multicenter prospective trauma registry-based study, performed in the University Medical Center Utrecht (UMCU), Utrecht, the Netherlands, John Hunter Hospital (JHH), Newcastle, Australia, and Harborview Medical Center (HMC), Seattle, the United States. Inclusion: patients $\geq 18$ years, admitted in 2012, registered in the institutional trauma registry.

Results In UMCU, JHH, and HMC, respectively, 955, 1146, and 4049 patients met the inclusion criteria of which 300, 412, and 1375 patients with Injury Severity Score (ISS) $>15$. Mean ISS was higher in JHH $(13.5 ; p<0.001)$ and HMC $(13.4 ; p<0.001)$ compared to UMCU (11.7). Unadjusted mortality: UMCU $=6.5 \%$, JHH $=3.6 \%$, and $\mathrm{HMC}=4.8 \%$. Adjusted odds of death: $\mathrm{JHH}=0.498[95 \%$ confidence interval (CI) 0.303-0.818] and $\mathrm{HMC}=0.473(95 \%$ CI $0.325-0.690)$ compared to UMCU. HMC compared to JHH was $1.002(95 \%$ CI 0.664-1.514). Odds of death patients ISS $>15: \mathrm{JHH}=0.507$ (95\% CI 0.300-0.857) and HMC $=0.451(95 \%$ CI 0.297-0.683) compared to UMCU. HMC $=0.931$ (95\% CI 0.608-1.425) compared to JHH. TRISS analysis: UMCU: $\mathrm{Ws}=0.787, \mathrm{Z}=1.31, M=0.87$; JHH, Ws $=3.583, Z=6.7, M=0.89 ; \mathrm{HMC}, \mathrm{Ws}=3.902, Z=14.6$, $M=0.84$.

Conclusion This study demonstrated substantial differences across centers in patient characteristics and mortality, mainly of neurological cause. Future research must investigate whether the outcome differences remain with nonfatal and long-term outcomes. Furthermore, we must focus on the development of a more valid method to compare systems.
\end{abstract}

Amy C. Gunning

a.c.gunning@umcutrecht.nl

1 Department of Trauma Surgery, University Medical Center Utrecht, Suite: G04.228, Heidelberglaan 100,

3584 CX Utrecht, The Netherlands

2 Department of Traumatology, John Hunter Hospital and University of Newcastle, Newcastle, Australia
3 Department of Pediatrics, Epidemiology, and Harborview Injury Prevention and Research Center, University of Washington, Seattle, WA, USA

4 Department of Trauma, Burns and Critical Care Surgery, Harborview Medical Center, University of Washington, Seattle, WA, USA 


\section{Introduction}

Trauma systems were developed during the last 40 years to coordinate and improve the care for the injured [1]. A regionalized care approach was established with a combination of levels of designated trauma centers. Evaluations have demonstrated the efficacy in terms of better triage and improved patient outcomes [2-5].

The verified trauma centers in a trauma system follow the criteria outlined by the American College of Surgeons Committee on Trauma (ACS-COT) [1]. Although the aim of a trauma system is similar in each country, major differences and variations exist in the designation and elements comprising the system both within and across countries. For instance, differences in geographical service areas, trauma mechanisms, demographic injury patterns, trauma patient volumes, and trauma resources, such as the availability of dedicated trauma teams, trauma surgeons, and operation facilities. Each of these factors may have an influence on patient characteristics and the outcome of patients. Lessons can be learned from different system designs, therefore it is important for trauma systems to compare and benchmark other systems.

In this study, we examine three international trauma systems by comparing the demographic patterns and patient outcomes in three Level I trauma centers.

\section{Methods and patient setting}

\section{Study design}

We performed an international multicenter trauma registrybased study with prospectively collected data at three Level I trauma centers functioning within verified trauma systems:

- University Medical Center Utrecht (UMCU), Utrecht, the Netherlands.

- John Hunter Hospital (JHH), Newcastle, Australia.

- Harborview Medical Center (HMC), Seattle, United States.

Each tertiary care facility has a central role and leadership within a trauma system and has adequate depth of resources and personnel to care for the most severely injured patients [1]. Data on all trauma admissions are registered in the institutional trauma registry and the national trauma registry, which includes the same variables as the Major Trauma Outcome Study database (MTOS) [6].

This study is conducted in accordance with the principles of the Declaration of Helsinki [7] and Good Clinical Practice Guidelines [8]. The Institutional Review Board of the UMCU, JHH, and HMC approved the study.
University Medical Center Utrecht

In 1999, regionalized trauma care was instituted in the Netherlands. In the Dutch trauma system, 11 Level I trauma centers were established, each covering a specific region in the Netherlands. The UMCU officially became a Level I trauma center in 2000 and covers the central region of the Netherlands. Four Level II and III trauma centers are connected to this network. The longest distance between the centers is approximately $50 \mathrm{~km}$. The Medical Air Assistance of the Royal Dutch Touring Club (ANWB) provides the prehospital care in the air, and the Regional Ambulance Care Utrecht (RAVU) on the road.

The trauma registry includes all direct trauma admissions from the emergency department (ED).

\section{John Hunter Hospital}

The first introduction of a system for trauma care in Australia was in New South Wales (NSW); in 1988, it became Australia's first state trauma plan and was implemented in NSW in 1992 [9]. JHH is a state-designated Level I trauma center, verified by the Royal Australasian College of Surgeons. It is the only major tertiary referral hospital for the Hunter New England region. The John Hunter trauma service was established in 2005.

The prehospital care in the Hunter region is provided by the Ambulance Service of NSW and utilizes both road and helicopter primary retrieval from the trauma scene. Two helicopters serve the area. By protocol, all major trauma patients in the Hunter New England region are transported to the Level I trauma center.

All trauma patients registered in the trauma registry had a Full Trauma Team Activation or an ISS $>15$.

\section{Harborview Medical Center}

The first trauma systems were developed in the United States (US) in the late 1960s [10, 11]. HMC was the first designated Level I trauma center in the state of Washington and verified in 1993. It serves as the only Level I trauma center in four states, Washington, Alaska, Idaho, and Montana. The majority of the trauma patients, approximately $95 \%$, come from the state of Washington.

The prehospital transportation is provided by ground ambulances from the Seattle Emergency Medical Service (EMS) system and the King County EMS system, and the air ambulance system is managed by Airlift Northwest [12].

In $\mathrm{HMC}$, all trauma admissions are registered in the institutional trauma registry, except for patients aged $\geq 65$ years with an isolated neck of femur fracture.

An overview of the key differences of the three trauma centers is presented in Table 1 [13-19]. 
Table 1 Key demographic and trauma center differences

\begin{tabular}{llll}
\hline & UMCU & JHH & HMC \\
\hline Country & The Netherlands & Australia & The United States \\
Service area $\left(\mathrm{km}^{2}\right)$ & 1500 & 130,000 & 185,000 \\
Residents $(\mathrm{n})$ & $1,300,000$ & 840,000 & $7,000,000$ \\
Verification level trauma center & Level I & Level I & Level I \\
Annually total hospital patient volume & \pm 35000 & \pm 40000 & \pm 19000 \\
Annually trauma patient volume & \pm 1300 & \pm 4500 & \pm 6000 \\
Annually trauma patient volume, ISS $>15$ & \pm 375 & \pm 425 & \pm 2000 \\
Surgeons involved in acute trauma care & 6 & 4 & 10 \\
\hline
\end{tabular}

$\mathrm{km}$ kilometers, $n$ number of patients, and ISS Injury Severity Score

\section{Patients}

All consecutive patients, aged 18 years and older, with blunt or penetrating injury admitted to each of the trauma centers between January 1, 2012 and December 31, 2012 were selected from the institutional trauma registry. Patients dead on arrival in ED, or with injuries due to burns, electrocution, or drowning were excluded.

\section{Data}

Data were collected from the institutional trauma registry and electronic medical records. The collected data were age, gender, trauma mechanism, Glasgow Coma Score (GCS), systolic blood pressure (SBP), respiratory rate (RR), Revised Trauma Score (RTS), Abbreviated Injury Scale (AIS) score (version 2005), Injury Severity Score (ISS), survival probability, hospital length of stay (H-LOS) in days, intensive care unit length of stay (ICU-LOS) in days, in-hospital mortality, and cause of death.

A patient with an ISS above 15 was considered a severely injured patient. Patients with an AIS score in the head region were noted as a patient with neurotrauma, an AIS $>3$ was scored as severe neurotrauma.

\section{Statistical analysis}

We used multiple imputation methods for missing data of the physiological parameters (i.e., GCS, SBP, and RR). Studies have demonstrated that multiple imputation leads to less biased results [20]. Furthermore, we have demonstrated in a previous study that multiple imputation is a reliable method despite the percentages of missing data [21]. In UMCU, GCS, SBP, and RR were missing in, respectively, 29.2, 21.9, and $65.3 \%$ of the patients. In JHH, GCS, SBP, and RR were missing in, respectively, $14.8,11.3$, and $11.4 \%$ of the patients. In HMC, in 12.0, 0.2 , and $1.1 \%$ of the patients, respectively, GCS, SBP, and RR were missing.
Trauma and Injury Severity Score (TRISS) methodology was used to compare the trauma center performances. We have calculated the standardized Ws score, proposed by Hollis et al. [22]., Z score, and M statistic. The Ws score states the number of excess survivors compared to the baseline database (MTOS database) per 100 patients [6]. The significance of the Ws score is determined by the $\mathrm{Z}$ score, a value below -1.96 and above 1.96 indicates, respectively, a significantly worse and better performance. The M statistic describes the injury severity mix between the studied institution and the baseline database, a value below 0.88 indicates a disparity in the severity match between the two groups [23].

A multivariable logistic regression model adjusted for confounders was used to calculate odds ratio (OR). The OR was used as an estimate of the relative risk of death, given the outcome was rare. The covariates adjusted for were age, ISS, RTS, and severe neurotrauma, all parameters known to influence the outcome substantially. To achieve comparable populations, we have standardized the inclusion criteria and performed a subanalysis for the odds of deaths in patients with ISS $>15$.

Continuous variables were compared with independent sample Student's t-test and the Mann-Whitney U-test. Categorical variables were compared with the Chi-square test. Mean values are presented with their standard deviations (SD) and medians with their interquartile range (IQR).

The imputation of missing data and the statistical analysis were performed with SPSS, version 20.0 (IBM Corp., Armonk, NY) for Windows. Significance of statistical differences was attributed to $\mathrm{p}<0.05$.

\section{Results}

An overview of the study patients is shown in Fig. 1. In total, 955 patients met the inclusion criteria from UMCU, 1146 patients from $\mathrm{JHH}$, and 4049 patients from HMC. 


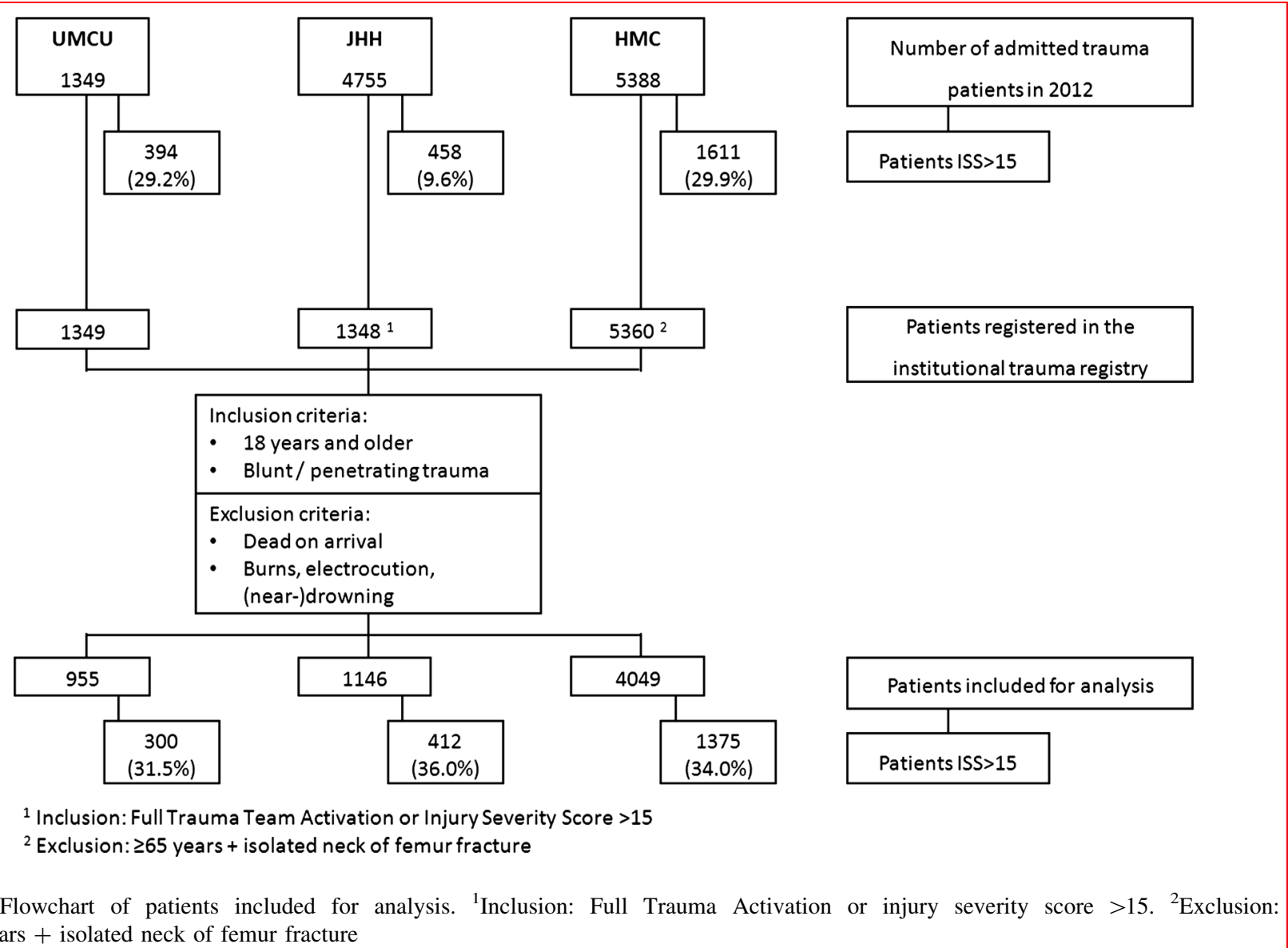

Fig. 1 Flowchart of patients included for analysis. ${ }^{1}$ Inclusion: Full Trauma Activation or injury severity score $>15 .{ }^{2}$ Exclusion:
$\geq 65$ years + isolated neck of femur fracture

Patients in UMCU were slightly older, more likely to be female and had longer hospital lengths of stay. Penetrating trauma was more common at HMC compared to UMCU $(p<0.001)$ and $\mathrm{JHH}(p<0.001)$. Compared to the UMCU population mean, ISS was higher in both $\mathrm{JHH}(p<0.001)$ and HMC $(p<0.001)$. The proportion of patients with neurotrauma was highest in $\mathrm{JHH}$ followed by UMCU and HMC. UMCU had the highest proportion of patients with severe neurotrauma. Almost $50 \%$ of the patients in $\mathrm{HMC}$ were admitted to the ICU in contrast to $20.6 \%$ in UMCU and $15.8 \%$ in $\mathrm{JHH}$. Though the ICU patients in UMCU and JHH were more severely injured [median ISS, respectively, 21 (13-27) and 25 (17-34)] compared to HMC [median ISS 17 (10-26)]. Unadjusted mortality was significantly higher at UMCU compared to JHH and HMC. All these patient characteristics are presented in Table 2.

After adjustment, the OR for mortality for all patients at JHH and HMC was 0.498 [95\% confidence interval (CI) $0.303-0.818$ ] and 0.473 (95\% CI 0.325-0.690), respectively, compared to UMCU. The odds for death in HMC compared to JHH was 1.002 (95\% CI 0.664-1.514).

For the severely injured patients, the adjusted ORs for death were 0.507 (95\% CI 0.300-0.857) in JHH and 0.451
(95\% CI 0.297-0.683) in HMC compared to UMCU (Table 3). The odds for death for the severely injured patients in HMC was 0.931 (95 \% CI 0.608-1.425) compared to JHH. Unadjusted causes of death are presented in Table 4.

In Table 5, we observed a positive number of excess survivors in $\mathrm{JHH}$ and HMC compared to the baseline population. TRISS analysis in the UMCU population showed no significant difference from the baseline database, and therefore the number of excess survivors equals zero. The $\mathrm{M}$ score of UMCU and HMC was below the allowed value of 0.88 .

\section{Discussion}

In this study, we have described differences between international trauma systems by comparing the demographic patterns and outcomes of trauma patients in three international Level I trauma centers.

A significant difference in the results was the survival rates at the trauma centers. The crude mortality in UMCU was significantly higher compared to $\mathrm{JHH}$ and HMC. 
Table 2 Patient characteristics

\begin{tabular}{|c|c|c|c|}
\hline & UMCU & JHH & HMC \\
\hline Patients, $\mathrm{n}$ & 955 & 1146 & 4049 \\
\hline Patients ISS > $15(\mathrm{n})(\%)$ & $300(31.5)$ & $412(36.0)^{\mathrm{a}}$ & $1375(34.0)$ \\
\hline \multicolumn{4}{|l|}{ Type of injury } \\
\hline Blunt (n) (\%) & $889(93.1)$ & $1086(94.8)$ & $3508(86.6)^{\mathrm{ab}}$ \\
\hline Penetrating (n) (\%) & $66(6.9)$ & $60(5.2)$ & $541(13.4)^{\mathrm{ab}}$ \\
\hline Mean age (SD) & $51.5(21.057)$ & $45.7(20.284)^{\mathrm{a}}$ & $49.5(20.599)^{\mathrm{ab}}$ \\
\hline \multicolumn{4}{|l|}{ Gender } \\
\hline Male (n) (\%) & $608(63.6)$ & $836(72.9)^{\mathrm{a}}$ & $2741(67.7)^{\mathrm{ab}}$ \\
\hline Female (n) $(\%)$ & $348(36.4)$ & $310(27.1)^{\mathrm{a}}$ & $1308(32.2)^{\mathrm{ab}}$ \\
\hline \multicolumn{4}{|l|}{ ISS } \\
\hline Mean (SD) & $11.7(9.735)$ & $13.5(10.514)^{\mathrm{a}}$ & $13.4(10.977)^{\mathrm{a}}$ \\
\hline Median (IQR) & $9(4-17)$ & $10(5-17)^{\mathrm{a}}$ & $10(5-17)^{\mathrm{a}}$ \\
\hline \multicolumn{4}{|l|}{ ISS, patients ISS $>15$} \\
\hline Mean (SD) & $23.4(7.551)$ & $24.4(9.940)^{\mathrm{a}}$ & $25.5(10.170)^{\mathrm{a}}$ \\
\hline Median (IQR) & $21(17-26)$ & $22(17-28.5)^{\mathrm{a}}$ & $22(17-29)^{\mathrm{a}}$ \\
\hline \multicolumn{4}{|l|}{ ISS subgroups } \\
\hline ISS $<9$ (median, IQR) & $4(2-5)$ & $5(4-6)^{\mathrm{a}}$ & $5(4-5)^{\mathrm{a}}$ \\
\hline ISS 9-15 (median, IQR) & $10(9-12)$ & $10(9-13)^{\mathrm{a}}$ & $10(9-12)^{\mathrm{a}}$ \\
\hline ISS 16-24 (median, IQR) & $17(17-21)$ & $17(17-21)$ & $17(17-21)$ \\
\hline ISS 24-40 (median, IQR) & $27(25-29.75)$ & $29(25-33)$ & $29(26-33)^{\mathrm{a}}$ \\
\hline ISS $>40$ (median, IQR) & $43(41-49)$ & $50(45-57)^{\mathrm{a}}$ & $48(43-57)^{\mathrm{a}}$ \\
\hline RTS, mean (SD) & $7.31(0.997)$ & $7.44(0.964)^{\mathrm{a}}$ & $7.17(1.316)^{\mathrm{a}}$ \\
\hline Mean Ps (SD) & $0.92(0.162)$ & $0.93(0.154)^{\mathrm{a}}$ & $0.90(0.194)^{\mathrm{ab}}$ \\
\hline Neurotrauma (n) (\%) & $457(47.9)$ & $690(60.2)$ & $1702(42.0)$ \\
\hline Mild $($ AIS $\leq 3)(n)(\%)$ & $261(27.3)$ & $481(42.0)^{\mathrm{a}}$ & $989(24.4)^{\mathrm{b}}$ \\
\hline Severe $($ AIS $\geq 4)(n)(\%)$ & $196(20.5)$ & $209(18.2)$ & $712(17.6)^{\mathrm{a}}$ \\
\hline ICU admission (n) (\%) & $197(20.6)$ & $181(15.8)^{\mathrm{a}}$ & $1954(48.3)^{\mathrm{ab}}$ \\
\hline \multicolumn{4}{|l|}{ H-LOS, days } \\
\hline Mean (SD) & $10.5(13.331)$ & $8.9(14.347)^{\mathrm{a}}$ & $8.2(11.301)^{\mathrm{a}}$ \\
\hline Median (IQR) & $6(2-13)$ & $5(3-9)^{\mathrm{a}}$ & $5(2-9)^{\mathrm{a}}$ \\
\hline \multicolumn{4}{|l|}{ ICU-LOS, days } \\
\hline Mean (SD) & $7.0(10.438)$ & $6.7(6.995)$ & $5.4(5.853)$ \\
\hline Median (IQR) & $3(2-9)$ & $4(2-8)$ & $3(3-6)$ \\
\hline Mortality & $62(6.5)$ & $41(3.6)^{\mathrm{a}}$ & $194(4.8)^{\mathrm{a}}$ \\
\hline Mortality, patients ISS $>15$ & $54(18 \%)$ & $40(9.7 \%)^{\mathrm{a}}$ & $171(12.4 \%)^{\mathrm{a}}$ \\
\hline
\end{tabular}

a significantly different from UMCU

b significantly different from JHH

Adjusted for confounders, the odds for death in $\mathrm{JHH}$ and HMC was much lower compared to UMCU (Table 3). Both crude and adjusted mortality did not significantly differ between $\mathrm{JHH}$ and HMC.

The difference was also demonstrated with the TRISS method. These analyses showed that both HMC and JHH performed better than the international standard. The performance of UMCU was equal to this standard. (Table 5) Based on these results, we could state that HMC and JHH performed better than UMCU. However, at both HMC and
UMCU, the M score was just below its threshold value, suggesting a disparity in injury severity match in these populations. Several authors have stated that TRISS has become an inappropriate tool to compare trauma center performances. It has an unacceptably high misclassification rate in severely injured patients, and the TRISS coefficients are drifting out of calibration [24-26]. Furthermore, TRISS is thought to underestimate the severity in penetrating injury and could have caused an underestimation of the $\mathrm{W}$ and $\mathrm{Z}$ score. TRISS is also known to overestimate the 
Table 3 Adjusted odds for death, OR (95\% CI)

\begin{tabular}{lll}
\hline & All patients & Patients ISS $>15$ \\
\hline UMCU versus JHH & $0.498(0.303-0.8180), p=0.006$ & $0.507(0.300-0.857), p=0.011$ \\
UMCU versus HMC & $0.473(0.325-0.690), p<0.001$ & $0.451(0.297-0.683), p<0.001$ \\
JHH versus HMC & $1.002(0.664-1.514), p=0.991$ & $0.931(0.608-1.425), p=0.742$ \\
\hline
\end{tabular}

Table 4 Causes of death

\begin{tabular}{llll}
\hline & UMCU & JHH & HMC \\
\hline Exsanguination & $3(4.8)$ & $4(9.8)$ & $14(7.2)$ \\
CNS injury & $42(67.7)$ & $33(80.5)^{\mathrm{a}}$ & $115(59.3)^{\mathrm{a}}$ \\
Resp failure/PNA/ARDS & $8(12.9)$ & $1(2.4)^{\mathrm{a}}$ & $37(19.1)^{\mathrm{b}}$ \\
Sepsis & 0 & 0 & $4(2.1)$ \\
SOF/MOF & $5(8.1)$ & $1(2.4)$ & $7(3.6)^{\mathrm{a}}$ \\
Cardiac & 0 & $2(4.9)$ & $8(4.1)$ \\
Multiple injuries & $2(3.2)$ & 0 & $5(2.6)$ \\
Other (CVA) & 0 & 0 & $1(0.5)$ \\
Unknown & $2(3.2)$ & 0 & $3(1.5)$ \\
\hline
\end{tabular}

a significantly different from UMCU

b significantly different from JHH

Table 5 TRISS analysis

\begin{tabular}{lllc}
\hline & UMCU & JHH & HMC \\
\hline Ws & 0.787 & 3.583 & 3.902 \\
$Z$ & 1.31 & 6.7 & 14.6 \\
$M$ & 0.87 & 0.89 & 0.84 \\
\hline
\end{tabular}

severity in patients who are intubated for presumed head injury in the presence of intoxicating substance. This could not be addressed in this study because we did not have these specific patient data.

Furthermore, the large differences between service areas in the various countries might influence the prehospital times substantially. The prehospital times in JHH and HMC are longer, therefore similarly injured patients might have worse physiological parameters at the time of arrival which influences the RTS [23]. Because of the substantial weight of the RTS in the TRISS model, this might lead to different mortality predictions in similar patients and qualify a trauma center incorrectly as an outlier [27].

Though the TRISS methodology is limited, it is the only benchmark we currently have across separate trauma systems. We have to readdress and update the TRISS method and search for a solution to cope with the demographic differences in the trauma populations.

The differences in mortality in this study could be partially assigned to the difference in patient volumes in the centers. Several authors have described a positive volume- outcome association for trauma patients [28-30]. In the current literature, there is no exact definition for high- or low-volume trauma centers, but most would consider UMCU a low-volume center, JHH a moderate, and HMC a high-volume center. In our opinion, in high-volume centers, three key factors attribute to better outcomes: the overall focus is better oriented toward the trauma patient, the presence of highly dedicated trauma teams, and the individual experience of the trauma surgeon. In the UMCU, $4 \%$ of the admissions are trauma related, compared to $11 \%$ at $\mathrm{JHH}$ and over $30 \%$ at HMC $[13,14,17]$. Furthermore, the numbers of severely injured patients treated per trauma surgeon is substantially higher in $\mathrm{JHH}$ (>100 patients/surgeon) and HMC (>200 patients/surgeon) compared to UMCU (approximately 60 patients/surgeon).

Our data revealed a discrepancy in the causes of death demonstrated between the centers. The majority of patient deaths in all three centers were following CNS injuries, with $\mathrm{JHH}$ being more than $80 \%$. The cause is unclear, but may relate in part to transport times. There is a higher proportion of patients with neurotrauma in $\mathrm{JHH}(60.2 \%)$, although the majority were only mild injuries $(70 \%)$. Whereas, the higher proportion of CNS injury deaths in UMCU (68\%) compared to HMC $(60 \%)$ could be partially explained by the higher proportion of patients with severe neurotrauma in the UMCU population (21 vs $18 \%$ ). The proportion of patients who died from exsanguination was the lowest at UMCU (5 \%), which may be a consequence of the much smaller service area and shorter prehospital times.

Importantly, different cultural policies regarding withdrawal of treatment with inevitable death or brain death may exist at each institution, and might have distorted the in-hospital mortality rates. There were no essential differences in discharge destinations or supportive data that suggested different discharge rates to specialized high care facilities or hospices (data not shown here). In future research, long-term mortality, and nonfatal outcomes such as the quality of life among the survivors should be addressed to eliminate some of these potential biases.

Similarly, we observed a large difference in the number of ICU admissions between the trauma centers (Table 2). This can be explained by the different policies and the availability of ICU beds in the hospitals. While patients in various conditions are admitted at the ICU in HMC, a patient in UMCU or JHH is only admitted at the ICU in critical 
condition when close monitoring or ventilation is indicated. As presented in the results, the higher median ISS of the ICU patients in UMCU and JHH supports these thoughts.

Several other reasons could contribute to the differences in outcome and should be explored in future studies.

Our data have several weaknesses. There is a difference in the inclusion criteria for the trauma registries which could have influenced the results, but should be controlled by examine outcomes with ISS $>15$ only. Elderly patients with an isolated neck of femur fracture are registered in the UMCU trauma registry, which may be a surrogate for unrecognized comorbidities [31]. Though, the number of these patients in UMCU is very low and therefore the influence on the analysis very minimal $[32,33]$.

This study demonstrated the demographic patterns and patient outcomes of trauma patients in Level I trauma centers in three international trauma systems. Besides the differences in patient characteristics and causes of death, a substantial difference in the mortality was demonstrated, mainly from neurological injury. Future research should reveal whether the outcome differences between the trauma centers still exist when nonfatal and long-term outcomes are compared. Furthermore, we must continue to benchmark and compare different trauma care systems with valid and reliable methods and identify strengths and weaknesses of systems in order to further inform trauma systems globally.

Acknowledgments The authors thank Angela Fischer from JHH and Laura Hennessy from HMC for their contribution in the initiation of the study in the hospitals. The authors thank the data collectors of the participating hospitals for providing data for this study. Furthermore, the authors thank the Netherlands Organisation for Scientific Research for the financial support of the study. Amy Gunning has received a personal grant from the Netherlands Organisation for Scientific Research to conduct this study.

\section{Compliance with ethical standards}

Conflict of interest The authors declare no conflicts of interest.

Open Access This article is distributed under the terms of the Creative Commons Attribution 4.0 International License (http://crea tivecommons.org/licenses/by/4.0/), which permits unrestricted use, distribution, and reproduction in any medium, provided you give appropriate credit to the original author(s) and the source, provide a link to the Creative Commons license, and indicate if changes were made.

\section{References}

1. American College of Surgeons Committee on Trauma (2006) Resources for optimal care of the injured patient 2006. American College of Surgeons, Chicago

2. MacKenzie EJ, Rivara FP, Jurkovich GJ et al (2006) A national evaluation of the effect of trauma-center care on mortality. N Engl J Med 354:366-378
3. Nathens AB, Jurkovich GJ, Rivara FP et al (2000) Effectiveness of state trauma systems in reducing injury-related mortality: a national evaluation. J Trauma 48:25-30

4. Twijnstra MJ, Moons KG, Simmermacher RK et al (2010) Regional trauma system reduces mortality and changes admission rates: a before and after study. Ann Surg 251:339-343

5. Celso B, Tepas J, Langland-Orban B et al (2006) A systematic review and meta-analysis comparing outcome of severely injured patients treated in trauma centers following the establishment of trauma systems. J Trauma 60:371-378

6. Champion HR, Copes WS, Sacco WJ et al (1990) The major trauma outcome study: establishing national norms for trauma care. J Trauma 30:1356-1365

7. The declaration of Helsinki (2013) http://www.wma.net/en/ 30publications/10policies/b3/. Accessed 24 Feb 2014

8. The good clinical practice guidelines (2002) http://www.ema. europa.eu/docs/en_GB/document_library/Scientific_guideline/ 2009/09/WC500002874.pdf. Accessed 24 Feb 2014

9. NSW Health. New South Wales Institute of Trauma and Injury Management. The NSW Trauma Registry profile of serious to critical injuries (2006) Available at: http://www.health.nsw.gov. au/pubs/2008/pdf/trauma_profile_2006.pdf. Accessed February 24, 2014

10. Cowley RA, Scanlan E (1979) University trauma center: operation, design and staffing. Am Surg 45:79-85

11. Boyd DR, Dunea MM, Flashner BA (1973) The Illinois plan for a statewide system of trauma centers. J Trauma 13:24-31

12. Roudsari BS, Nathens AB, ArreolaRisa C et al (2007) Emergency Medical Service (EMS) systems in developed and developing countries. Injury 38:1001-1013

13. UMC Utrecht, Indicators 2012 (2012) http://www.umcutrecht.nl/ overumcutrecht/Kengetallen-2012.htm. Accessed 24 Feb 2014

14. NHPA, John Hunter Hospital (2012) http://www.myhospitals. gov.au/hospital/john-hunter-hospital/stays-in-hospital/admis sions. Accessed 24 Feb 2014

15. Dewar DC, Mackay P, Balogh Z (2009) Epidemiology of postinjury multiple organ failure in an Australian trauma system. ANZ J Surg 79:431-436

16. Trauma unit description John Hunter Hospital (2006) http://www. trauma.org/index.php/resources/fellowship/240/. Accessed 24 Feb 2014

17. UW Medicine, Harborview Medical Center Statistics 2012 (2012) http://www.uwmedicine.org/harborview/about. Accessed 24 Feb 2014

18. Harborview Medical Center. Trauma Report 2010. (2011) http:// www.uwmedicine.org/harborview/Documents/HARB_Trau maRpt_2010_FINAL\%20(2).pdf. Accessed 24 Feb 2014

19. Gruen RL, Jurkovich GJ, McIntyre LK et al (2006) Patterns of errors contributing to trauma mortality: lessons learned from 2,594 deaths. Ann Surg 244:371-380

20. Newgard CD, Haukoos JS (2007) Advanced statistics: missing data in clinical research-part 2: multiple imputation. Acad Emerg Med 14:669-678

21. Gunning AC, Leenen LP (2014) Applicability of the predictors of the historical trauma score in the present Dutch trauma population: modelling the TRISS predictors. J Trauma Acute Care Surg 77:614-619

22. Hollis S, Yates DW, Woodford M et al (1995) Standardized comparison of performance indicators in trauma: a new approach to case-mix variation. J Trauma 38:763-766

23. Boyd CR, Tolson MA, Copes WS (1987) Evaluating trauma care: the TRISS method. Trauma Score and the Injury Severity Score. J Trauma 27:370-378

24. Demetriades D, Chan L, Velmanos GV et al (2001) TRISS methodology: an inappropriate tool for comparing outcomes between trauma centers. J Am Coll Surg 193:250-254 
25. Cayten CG, Stahl WM, Murphy JG et al (1991) Limitations of the TRISS method for interhospital comparisons: a multihospital study. J Trauma 31:471-481

26. Rogers FB, Osler T, Krasne M et al (2012) Has TRISS become an anachronism? A comparison of mortality between the National Trauma Data Bank and Major Trauma Outcome Study databases. J Trauma Acute Care Surg 73:326-331

27. Glance LG, Osler T (2001) Beyond the major trauma outcome study: benchmarking performance using a national contemporary, population-based trauma registry. J Trauma 51:725-727

28. Konvolinka CW, Copes WS, Sacco WJ (1995) Institution and per-surgeon volume versus survival outcome in Pennsylvania's trauma centers. Am J Surg 170:333-340

29. Smith RF, Frateschi L, Sloan EP et al (1990) The impact of volume on outcome in seriously injured trauma patients: two years' experience of the Chicago Trauma System. J Trauma 30:1066-1075

30. Nathens AB, Jurkovich GJ, Maier RV et al (2001) Relationship between trauma center volume and outcomes. JAMA 285: $1164-1171$

31. Sampalis JS, Denis R, Lavoie A et al (1999) Trauma care regionalization: a process-outcome evaluation. J Trauma 46:565-579

32. Lansink KW, Gunning AC, Spijkers AT et al (2013) Evaluation of trauma care in a mature level I trauma center in the Netherlands: outcomes in a Dutch mature level I trauma center. World J Surg 37:2353-2359. doi:10.1007/s00268-013-2103-9

33. van Laarhoven JJ, van Lammeren GW, Houwert RM et al. (2015) Isolated hip fracture care in an inclusive trauma system: a trauma system wide evaluation. Injury 46(6):1042-1046 